\title{
Advance Planning in the Context of a Psychiatric Acute Care Hospital: Acceptance of a Trialogical Pilot Project
}

\author{
Daniela Blank \\ Kbo-Isar-Amper Klinikum, Haar, Germany \\ Ruth Weizel \\ Kliniken des Bezirks Oberbayern—Kommunalunternehmen, Munich, Germany \\ Markus Witzmann \\ Kliniken des Bezirks Oberbayern—Kommunalunternehmen, Munich, Germany; \\ University of Applied Sciences, Munich, Germany
}

\begin{abstract}
A joint crisis plan is a written consensus-orientated agreement between mental health service users and professionals. The instrument is used to regulate a potential future hospital treatment. At the Clinics of Upper Bavaria (kbo-Kliniken des Bezirks Oberbayern) representatives of the clinics, the organized relatives and those affected developed the pilot project “Joint Crisis Plan” in a trialogical process. The pilot project was evaluated between 2015 and 2017. The qualitative study looked at the experiences with the implementation of the instrument medical treatment agreement in different local settings. In doing so it considered the complex effects of "advance directives” on various levels such as the subjective importance and meaning as experienced by the patients, the effects on face-to-face interactions between patients and the medical staff, and the effects on institutional structures. And it considered the local influence—-such as medical cultures or economic and institutional conditions—on the implementation process and the use of this instrument. The results showed that patients need numerous competences to complete a joint crisis plan. Likewise the instrument affects self-efficacy and self-images of the patients and the relation between the patients and the clinical staff in a positive way. But if the joint crisis plan is insufficiently implemented, the instrument generates rather a mortification of the self.
\end{abstract}

Keywords: psychiatric advance directives, joint crisis plan, concept of self, grounded theory

\section{Introduction}

A joint crisis plan, in German called "Behandlungsvereinbarung", is a written consensus-orientated agreement between mental health service users and professionals. The instrument is used to regulate a potential future hospital treatment. It limits the course of action in a chronological subsequent setting. Based on the experience of the past, specific therapeutic alternatives or clinical conditions were in- or excluded. Joint crisis plans therefore anticipate the selection of appropriate practices and provide direction for future actions. In

Daniela Blank, Diplom-Soziologin (Univ.), Social Scientist, Kbo-Isar-Amper Klinikum, Haar, Germany.

Ruth Weizel, Master Mental Health (M.A.), Kliniken des Bezirks Oberbayern—Kommunalunternehmen, Munich, Germany.

Markus Witzmann, Ph.D., Professor, Bachelor Business Administration (BBA), Master Social Management (MSM), Politics and Economics (M.A.), Kliniken des Bezirks Oberbayern-Kommunalunternehmen, Munich, Germany; University of Applied Sciences, Munich, Germany. 
contrast to psychiatric advance directives, which are one-sided statements of intention, a joint crisis plan stresses the cooperative agreement (Henderson, Flood, Leese, Thornicroft, Sutherby, \& Szmukler, 2004).

With all the legislative changes (Directive on Patients' Rights, legally binding advance directives, guardianship law, decisions of the German constitutional court on forced medication) taking place in the last years, and the impact of new approaches that increasingly influence practical work, such as empowerment, resource-oriented therapeutic models and shared decision making, Advance Care Planning and joint crisis plans are frequently discussed in Germany. Although several studies have shown the existing interest in advance directives, albeit not to the same extent among patients, relatives and professionals (Srebnik, Russo, Sage, Peto, \& Zick, 2003; Swanson, Swartz, Hannon, Elbogen, Wagner, McCauley, \& Butterfield, 2003; Van der Ham, Voskes, van Kempen, \& Broerse, 2013; Bee, Owen, Baker, \& Lovell, 2015) and the need for facilitated advance planning (Sutherby, Szmukler, Halpern, Alexander, Thornicroft, Johnson, \& Wright, 1999; Elbogen, Swartz, van Dorn, Swanson, Kim, \& Scheyett, 2007; Srebnik et al., 2003; Swanson et al., 2003; Rittmannsberger \& Lindner, 2006), there are limited data on the experiences of the actors with the use of a completed medical treatment agreement in case of a new admission to the hospital and which resources (technical, personal, structural) are required for a best practice. Mainly the studies do not include data on testing the instrument in medical crises. In addition, the studies displayed an inconsistent assessment regarding the reduction of coercive actions and compulsory hospitalization (Henderson et al., 2004; Papageorgiou, King, Janmohamed, \& Davidson, 2002; Thorniecroft et al., 2013; Flood, Byford, Henderson, Leese, Thornicroft, Sutherby, \& Szumkler, 2006; Campell \& Kiesly, 2010; Rittmannsberger \& Lindner, 2006; R. Borbé, Jaeger, S. Borbé, \& Steinert, 2012; Dietz, Hildebrand, Pleininger-Hoffmann, Pörksen, \& Voelzke, 2002).

In this article, we describe initial experiences with a trial of joint crisis plans in Germany. At the Clinics of Upper Bavaria (kbo-Kliniken des Bezirks Oberbayern) representatives of the clinics, the organized relatives and those affected developed the pilot project "Joint Crisis Plan" in a trialogical process. The trialogical steering committee developed the text of the joint crisis plan and the conditions for the pilot project. Furthermore they were responsible for supervising the pilot project during implementation.

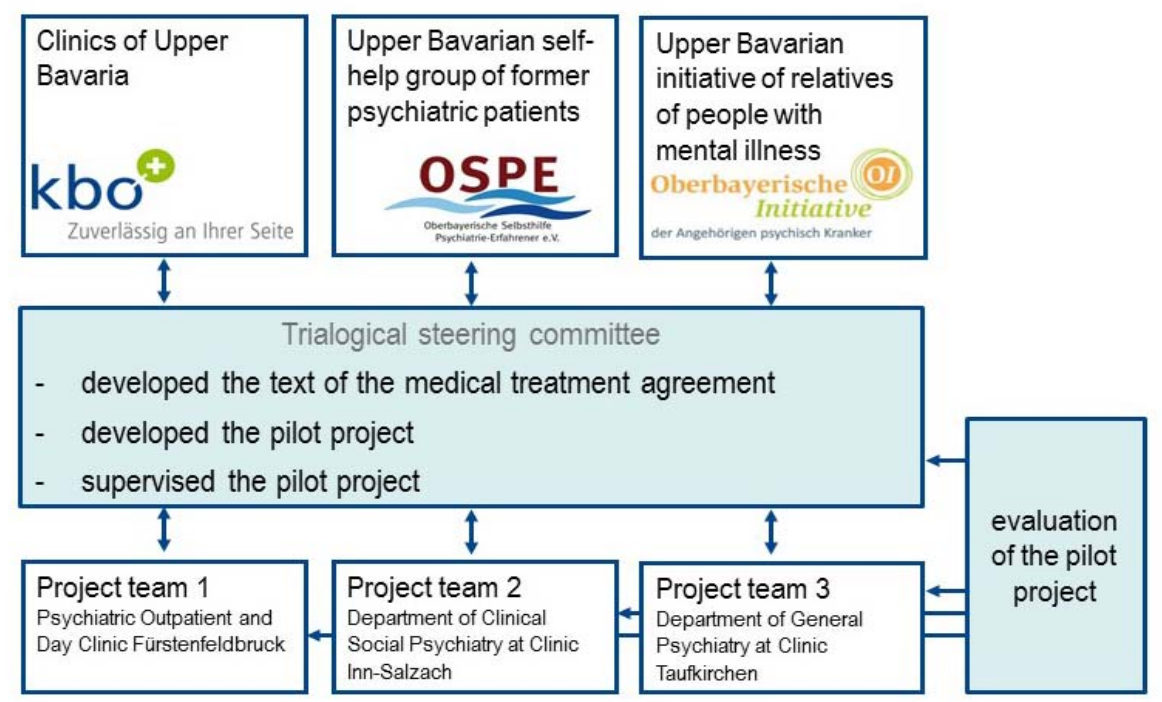

Figure 1. The trialogical structure of the pilot project. 
The associated process, its acceptance and effects on the treatment were evaluated in a model project from June 2015 to June 2017 at three different local settings: outpatient psychiatric clinic and day clinic Fürstenfeldbruck, inpatient clinic Inn-Salzach-Klinikum and Taufkirchen. Therefore the trial aimed

- to test and enhance the processes associated with the medical treatment agreement;

- to establish the medical treatment agreement as an integral component of advance care planning and ensure its acceptance by all parties involved;

- to identify and define the target group of patients, who will profit from advance planning;

- to reduce coercive actions, compulsory hospitalization and to promote voluntary treatment and hospitalization at the beginning of a psychiatric crisis.

The target group focused on people with mental illness who desire to declare their wishes and needs for a situation, in which they require (further) psychiatric hospitalization while being incapable of making their own decisions and giving consent to treatments. The pilot project actively invited patients into the program who had been in stationary psychiatric treatment before and were at a high risk of being hospitalized again in the near future. And also patients who had ICD 10 F20, F30 or F60 as their main diagnosis, who fulfilled the minimum criteria for compliance and motivation and were living in the area of the clinic. The content of treatment agreement includes the status of the contact person (e.g. confidant, commissioner, legal guardian), admission (e.g. desired station, referenced person), medication (e.g. current medication, incompatibilities), treatment (e.g. useful for anxiety, disorientation, suicidality), coercive treatment (e.g. experiences with coercive measures, notification) and the social situation.

\section{Method}

The study generates an understanding of practical experience with the instrument joint crisis plan and analyses the effects of the implemented interventions. The evaluation uses multiple instruments and a mixed-methods design: face-to-face, audio-taped, semi-structured interviews (individual and focus groups) and analysis of completed "medical treatment agreements" and medical records. The survey spanned a two year period, involved 14 patients combined from all included clinics, one relative and all staff members who are concerned with the daily practices of joint crisis plans (five doctors, one health care leader, three psychologists). Data collection, data analyses and theoretical development were based on the fundamental process of the grounded theory. Among other things, this included theoretical sampling, the coding of the data and the application of the coding paradigm (Strauss, 1994; Böhm, 2000).

\section{Results}

From June 2015 to June 2017, 98 patients concluded a joint crisis plan. In the course of that period, 36 of these patients required readmission to an inpatient clinic. The patients were actively invited into the program during the medical consultation in the outpatient or inpatient clinic as well as in a group psychoeducation for patients at the inpatient clinic conducted by psychologists.

\section{Competences and Resources}

The interviews showed that the process of completing a joint crisis plan requires numerous competences and resources. An organ donation card is also often considered, but there are obstacles to actively using this possibility. Likewise, an interest in a psychiatric advance directive does not lead straight forward to its 
completion. A joint crisis plan requires reading competence and an active transformation of one's own wishes and needs into written form. In addition, a treatment agreement requires the identification of the instrument with self-will and the transformation into one's own biography and environment. The review of the past (psychiatric crisis, medication history) and the re-forming of previous psychiatric crisis as future resources are integral parts of the work. Here is a fragment from one interview with a patient ${ }^{1}$ :

I thought about what is useful especially at the psychiatric ward one used to go. And partly I talked with my doctor about the hospital admission and the relapse and what is useful. Thus, he naturally suggested some properties, like psychiatric wards, and mixed with my own experiences I chose two wards where I wanted to go if I have a relapse.

Therefore this necessitates a minimum of positive experiences with the mental health care system to perceive the inpatient clinic as a partner. Likewise the reason for the hospital admission must be described as a medical problem which could be potentially repeated. The knowledge about the course of the own psychiatric crisis and the effects of previous medical treatments are the basis for completing a joint crisis plan. If sufficient knowledge is not available, then there is not enough information for implementing a joint crisis plan. Finally, a psychiatric advance directive needs resources in the living environment, like a contact person. These findings are congruent with other studies, that similarly documented numerous competences and resources required for completing a joint crisis plan (Amering, Stastny, \& Hopper, 2005; Swanson, Swartz, Elbogen, van Dorn, Ferron, Wagner, McCauley, \& Kim, 2006).

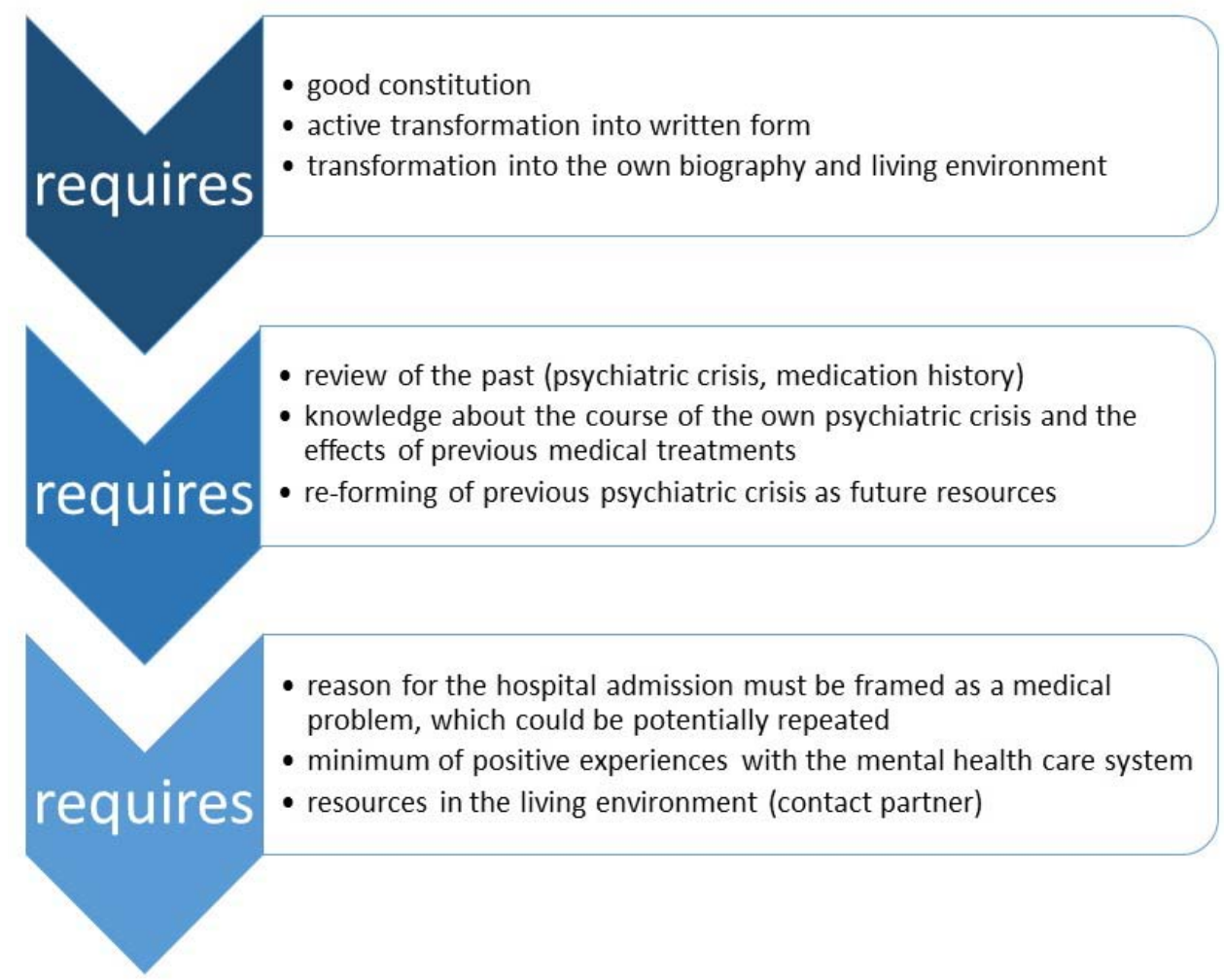

Figure 2. Competences and resources for completing a joint crisis plan.

\footnotetext{
${ }^{1}$ The original transcripts of interviews are written in German.
} 


\section{Expectations}

The study shows that the patient expectations are numerous and reach from minor effects and pragmatic facilities during the inpatient treatment to sustainable improvement of the mental health care system. This implies for instance an increase of information and speed in decision making in psychiatric crisis, a better supply with clothes and cosmetics and gives orientation for patients what they can expect from the professionals:

They know immediately what I want (...) and they don't send me where I didn't want to go.

Why I complete that, is simply spoken, the moment when you lost your everyday life, I mean, when I have a relapse (-) you are quickly overwhelmed by many things in, the living environment like myself, (-) that there is something where you can hold on to, what is previously cleared up for yourself and agreed (-) to know how it will continue.

Furthermore the study shows, patients see a joint crisis plan as a useful standard, because it represents the self as being capable of decision making, strong-willed and self-determined despite the loss of self-control in a psychiatric crises. A joint crisis plan is therefore a strategy to reduce the limitation of the self. Likewise completing a psychiatric advance directive means an increase of self-determination and generates possibilities for self-actualization. This interrelation becomes manifest in the interviews in the figure of being a full aged citizen (“mündiger Bürger”) or of being on a par with somebody (“auf gleicher Augenhöhe sein”):

I thought, this favoured patients to be treated as a full aged citizen and that people, well I mean they are partially supported, that they don't leave their personality and dignity quasi at the gates.

Because it goes more into the direction, where, well, uh, patient and doctor or clinic come together at eye level.

Finally, according to the patients, a joint crisis plan generates safeness, because

- contact persons were informed and you have somebody on your side;

- you know where you are during a psychiatric crisis;

- you know how you get treated;

- you know that nobody experienced with drugs;

- you can decide in a good condition which therapeutic treatments should be chosen;

- you are involved.

Because of the in- and exclusion of the course of action (e.g. drugs, treatment) a psychiatric advance directive transforms an open, contingent and risky setting into a reliable environment with acceptable and calculable risks ${ }^{2}$. As a consequence of the reciprocal appropriation of information, critical situations are expected and become a bit predictable.

\section{Preconditions}

With regard to the numerous expectations of the patients, following questions arise: Which preconditions precede a psychiatric advance directive? Which experience of the past leads to a designation with individual meaning? First the study shows that the experience of loss of interactional orientation and self-orientation precedes a psychiatric advance directive. Patients experience a crisis as confusion, which causes limitation of communication, and as being overtaxed with the living environment. Acute crisis leads to a (temporary) loss of

${ }^{2}$ Giddens highlighted the fact that safeness relies on a balance between confidence and acceptable risks (Giddens, 1996, p. 51). 
self-determination, to a loss of the decision-making role of the subject and a reversal of the autonomy of acting. Acute crisis generates a sense of instability, loss of control, uncertainty and a feeling of being dependent on others. These experiences of self-alienation and reversal of self-representation were a main motive for completing a joint crisis plan.

In addition, the study shows that negative experiences with the psychiatric health care system of the past are also significant reasons for completing a joint crisis plan. Interviewees describe the medical treatment in part as trial and error ("Ausprobieren"), incorrect and as an experience of being shut down (“Still-Gestellt-Werden”). Likewise the negative experiences become manifest as a deficit relationship between professionals and patients or a lack of involvement in the treatment plan. Patients illustrated this conjuncture for example as being addressed informally, limited information about the medical treatment and in the sense of not being on a par with somebody.

they said, now you get this drug (-) well (--) it is (-) there were situations were suddenly (-), after any ward round one drug appeared in this blue box and nobody really could answer the question: what's that?

Finally the negative experiences are bound to bad edificial and hygienic conditions and the use of coercive actions. The latter injures the autonomy of action and the representation of self because of their physical limitation ${ }^{3}$. This implies, according to the interviewees, a damage of self-identity (violation of human dignity, mental torture) and a disruption of the mutual trust between clinic and patients.

The third category of previous experiences of a joint crisis plan could be subsumed as "contingency of medical practices and health as fortune stroke of luck". Despite of the positive basic adjustment compared to the current metal health care system, the medical treatment is perceived as uncertain and unsteady, which implies possibly incalculable risks. Medical drugs contain health risks because of their unintentional side effects. The success of the medical treatment or state of health is described as a stroke of luck and not as an event that could be assuredly influenced by the actors. The previous experiences of a joint crisis plan are therefore the loss of self-orientation, self-alienation and reversal of self-representation in the course of a psychogenic crisis, negative experiences with the mental health care system and the uncertain or unsteady perception of the medical treatment as well. This suggests that the main motives for completing a joint crisis plan relate to the minimisation of these risky conditions. Thus, the underlying problem to which a joint crisis plan tries to find an adequate answer or rather the central category of this inquiry is the reversal of self-representation and of the autonomy of acting ${ }^{4}$.

\section{Consequences}

Joint crisis plans exert influence by generating self-actualisation, self-orientation, and self-assurance. They stimulate specific activations, like the reflection on previous experiences, the search for solutions or the organisation of individual arrangements for an acute psychiatric crisis. They foster coping with an illness, enable to transform the own experiences into a written form and initiate demands for medical consultations. According to the interviewees, joint crisis plans have a positive effect to the self-experience, because

\footnotetext{
${ }^{3}$ Goffmann (1961) illustrated this interrelation elaborately in his book Asylums: Essays on the Social Situation of Mental Patients and Other Inmates.

${ }^{4}$ According to Goffmann (1961) there are several practices for dealing with this reversal of self-representation and autonomy of acting, e.g. resistance to readmission or medical treatment, withdrawal of the patient's role, deviating practices.
} 
- professionals are required to gain information;

- professionals hold knowledge about the patients;

- the patient knows that someone would be informed;

- mistrust gets reduced due to the limitation of the scope of action;

- the feeling of being at someone mercy does not emerge.

These findings are congruent with other studies, which similarly documented numerous positives effects (Dietz et al., 2002; Swanson et al., 2006; Thornicroft et al., 2013; Drack-Schöneberger, Bleiker, Lengler, Blank, Rössler, \& Lay, 2015). The actual self-experience is positively influenced, since the processes of information collection and provision are systematically implemented and patients are still involved in decision-making processes despite their limited capacity to act ${ }^{5}$ :

I didn’t know what I have to face and what would be tested, and so on. I was distrustful and now I know I didn’t have to.

I have to say since that time there was a readmission (-) and I felt good, because of I realized during the ward round that the doctor immediately said: Hello, you don't tolerate all meds. He knows, he said, and now he considers, that I get something what I tolerate best. And that's what they're looking for. And I felt comfortable. And I felt safe, secure, well treated and I'm not afraid of the hospital and about the treatment (-) And I feel good.

A joint crisis plan has the ability to influence the emotional being in a positive way, establish mutual trust and, respectively, strengthen the relationship of trust. According to Giddens, psychiatric advance directives act as a point of access to the mental health system, which establish or preserve mutual trust (Giddens, 1996). On the other hand a joint crisis plan may produce the contrary unless they are not fully implemented ${ }^{6}$. If the written statement is in case of a readmission not reliably turned into action, it merely produces an injury of the representation of the self. The consequence of not reading and not acting strengthens the feeling of being at one’s mercy.

I mean, this increases a bit of that (--) feeling of psychiatry that already there: It still strengthened this being at their mercy (--) If one has the feeling (-) you sit down (-) write that down (-) take the trouble to deal with that, that also triggers things.

It turned the mental health system into a hierarchic setting and imparted a self-experience without self-worth and self-determination.

\section{Conclusion}

Completing a joint crisis plan is demanding. The previous experiences of a joint crisis plan are loss of self-orientation, self-alienation and reversal of self-representation in the course of a psychogenic crisis, negative experiences with the mental health care system and the perception of uncertainty or inconsistency regarding the medical treatment as well. The underlying problem to which a joint crisis plan tries to find an adequate answer is the reversal of self-representation and of the autonomy of acting. According to that, psychiatric advance directives foster self-orientation and confidence or, if not fully implemented, they may produce the contrary: an injury of the representation of the self.

\footnotetext{
${ }^{5}$ See also Sutherby et al., 1999; Thornicroft et al., 2013.

${ }^{6}$ See also Sutherby et al., 1999.
} 


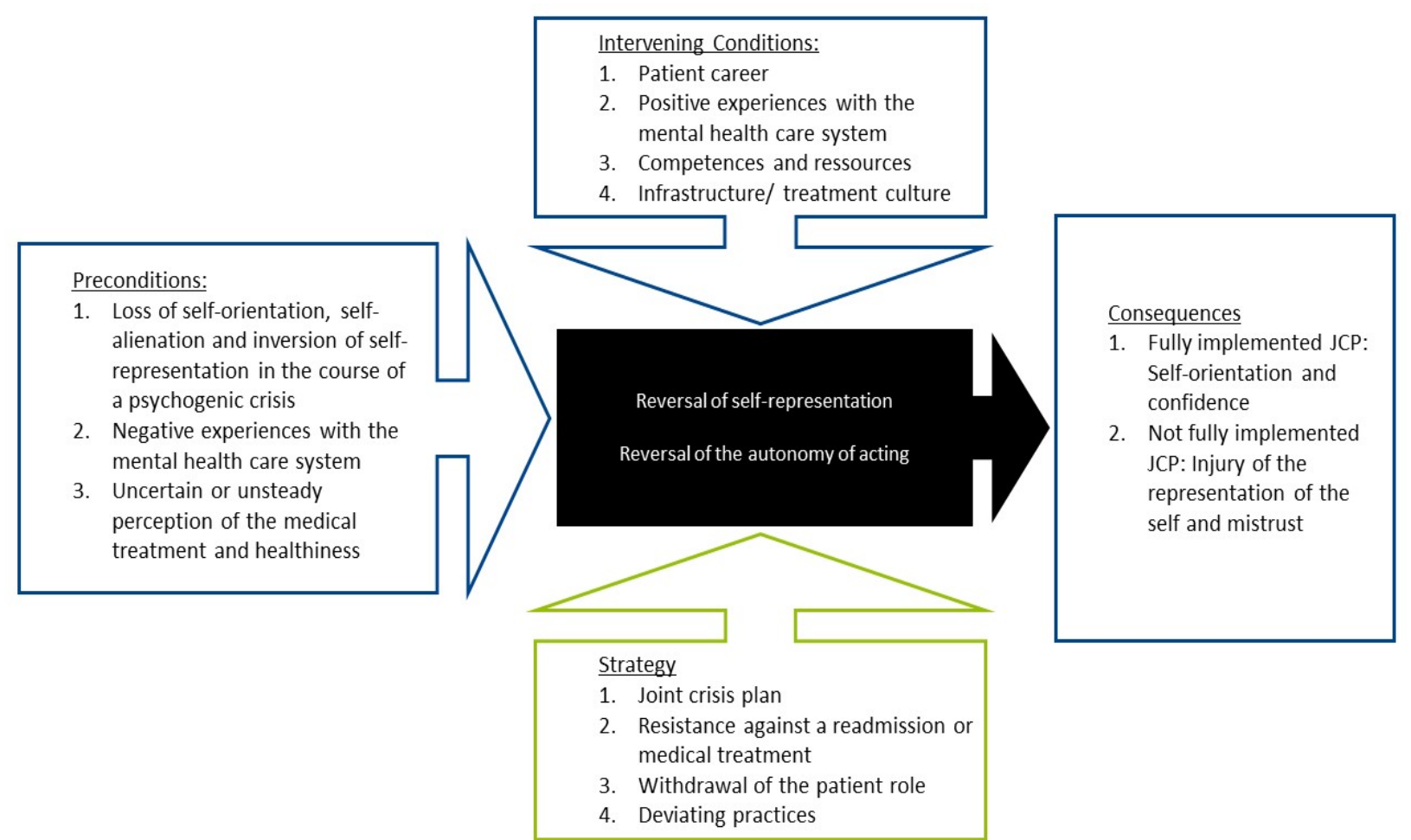

Figure 3. Relations between preconditions, intervening conditions, strategy, consequences, and the phenomenon "reversal of self-representation and of the autonomy of acting".

Therefore joint crisis planning is a proper tool to foster the cooperation between professionals, patients and relatives and to liberalize the metal health care system. It is a helpful opportunity for patients who want to declare their wishes and needs for a situation, in which they require (further) psychiatric hospitalization while being incapable of making their own decisions and giving consent to treatments. Because of the numerous competences and resources required on the one hand and the needed knowledge about clinical procedures on the other hand, the appropriate setting for completing, or facilitating, a joint crisis plan turns out to be the outpatient psychiatric clinic. To ensure a fully implemented proceeding, further modifications, like a simplified information pathway, and an improvement of the technical infrastructure is necessary to secure a fast and reliable access to the deposited information.

\section{References}

Amering, M. A., Stastny, P., \& Hopper, K. (2005). Psychiatric advance directives: Qualitative study of informed deliberations by mental health service users. British Journal of Psychiatry, 186, 247-252.

Bee, P., Owen, P., Baker, J., \& Lovell, K. (2015). Systematic synthesis of barriers and facilitators to service user-led care planning. The British Journal of Psychiatry, 207, 104-114.

Böhm, A. (2000). Theoretisches codieren: Textanalyse in der Grounded Theory. In U. Flick, E. von Kardorff, and I. Steinke (Hg.), Qualitative Forschung (pp. 475-485). Ein Handbuch, Hamburg: Rowohlt Taschenbuch.

Borbé, R., Jaeger, S., Borbé, S., \& Steinert, T. (2012). Anwendung psychiatrischer Behandlungsvereinbarungen in Deutschland. Ergebnisse einer bundesweiten Befragung. Nervenarzt 2012. 5.

Campell, A. L., \& Kiesly, S. R. (2010). Advance treatment directives for people with severe mental illness. Review. The Cochrane Library, 3.

Dietz, A., Hildebrand, M., Pleininger-Hoffmann, M., Pörksen, N., \& Voelzke, W. (2002). Behandlungsvereinbarung in der Akutpsychiatrie. Recht \& Psychiatrie, 20(1), 27-32. 
Drack-Schönenberger, T., Bleiker, M., Lengler, S., Blank, C., Rössler, W., \& Lay, B. (2015). Krisenkarten zur Prävention von Zwangseinweisungen. Krisenwarnzeichen, Behandlungswünsche und Bewältigungsstrategien aus Patientensicht. Psychiat Prax, 43(05), 253-259.

Elbogen, E., Swartz, M. S., van Dorn, R., Swanson, J. W., Kim, M., \& Scheyett, A. (2007). Competence to complete psychiatric advance directives: Effects of facilitated decision making. Lwa Hum Behav, 10.

Flood, C., Byford, S., Henderson, C., Leese, M., Thornicroft, G., Sutherby, K., \& Szumkler, G. (2006). Joint crisis plans for people with psychosis: Economic evaluation of a randomised controlled trial. BMJ, 333(7571).

Giddens, A. (1996). Konsequenzen der Moderne. Suhrkamp Taschenbuch Wissenschaft. Frankfurt a.M.

Goffmann, E. (1961). Asyle. Über die soziale Situation psychiatrischer Patienten und anderer Insassen. Suhrkamp. Frankfurt a.M.

Grätz, J., \& Brieger, P. (2012). Implementation of joint-crisis plans-A study of health care users and professionals. Psychiat Prax, 39, 388-393.

Henderson, C., Flood, C., Leese, M., Thornicroft, G., Sutherby, K., \& Szmukler, G. (2004). Effect of joint crisis plans on use of compulsory treatment in psychiatry: Single blind randomized controlled trial. BMJ, 329(7458).

Papageorgiou, A., King, M., Janmohamed, A., \& Davidson, O. (2002). Advance directives for patients compulsorily admitted to hospital with serious mental illness. BJP, 181, 513-519.

Rittmannsberger, H., \& Lindner, H. (2006). Erste Erfahrungen mit dem Angebot einer Behandlungsvereinbarung. Psychiat Prax, 33(2), 95-98.

Srebnik, D. S., Russo, J., Sage, J., Peto, T., \& Zick, E. (2003). Interest in psychiatric advance directives among high users of crisis services and hospitalization. Psychiatric Services, 54(7), 981-986.

Strauss, A. L. (1994). Grundlagen qualitativer Sozialforschung: Datenanalyse und Theoriebildung in der empirischen und soziologischen Forschung. München: Wilhelm Fink.

Sutherby, K., Szmukler, G. I., Halpern, A., Alexander, M., Thornicroft, G., Johnson, C., \& Wright, S. (1999). A study of “crisis cards” in a community psychiatric service. Acta Psychiatr Scand, 100(1), 56-61.

Swanson, J. W., Swartz, M. S., Elbogen, E. B., van Dorn, R. A., Ferron, J., Wagner, H. R., McCauley, B. J., \& Kim, M. (2006). Facilitated psychiatric advance directives: A randomized trial of an intervention to foster advance treatment planning among persons with severe mental illness. Am J Psychiatry, 163(11), 1943-1951.

Swanson, J. W., Swartz, M. S., Hannon, M. J., Elbogen, E. B., Wagner, H. R., McCauley, B. J., \& Butterfield, M. I. (2003). Psychiatric advance directives: A survey of persons with schizophrenia, familiy members, and treatment providers. International Journal of Forensic Mental Health, 2(1),73-86.

Thornicroft, G., Farrely, S., Szmukler, G., Birchwood, M., Waheed, W., Flach, C., Barrett, B., Byford, S., Henderson, C., Sutherby, K., Lester, H., Rose, D., Dunn, G., Leese, M., \& Marshall, M. (2013). Clinical outcome of joint crisis plans to reduce compulsory treatment for people with psychosis. The Lancet, 381(9878), 1634-1641.

Van der Ham, A., Voskes, Y., van Kempen, N., \& Broerse, J. E. W. (2013). The implementation of psychiatric advance directives: Experience from a Dutch crisis card initiative. American Psychological Association, 36(2), 119-121. 